\title{
Are Legal Disputes Just About the Money? Answers from Mediators on the Front Line
}

\author{
Harold I. Abramson \\ Touro Law Center, habramson@tourolaw.edu \\ Bennett Picker \\ Bill Marsh \\ Birgit Sambeth Glasner \\ Jerry Weiss
}

Follow this and additional works at: https://digitalcommons.tourolaw.edu/scholarlyworks

Part of the Dispute Resolution and Arbitration Commons

\section{Recommended Citation}

19 CARDOZO J. CONFLICT RESOL. 1 (2017) \& 35 ALTERNATIVES TO HIGH COST LITIG. 129 (Oct. 2017)

This Article is brought to you for free and open access by the Faculty Scholarship at Digital Commons @ Touro Law Center. It has been accepted for inclusion in Scholarly Works by an authorized administrator of Digital Commons @ Touro Law Center. For more information, please contact Iross@tourolaw.edu. 


\title{
ARTICLES
}

\section{ARE LEGAL DISPUTES \\ JUST ABOUT THE MONEY? \\ ANSWERS FROM MEDIATORS ON THE FRONT LINE*}

\author{
Hal Abramson, Bennett Picker, Bill Marsh, \\ Birgit Sambeth Glasner, and Jerry Weiss
}

\section{Introduction by Hal Abramson ${ }^{1}$}

Are most disputes in mediation just about money? That's an old and familiar question that many lawyers still seem to reply to with an emphatic "yes." Mediated cases are frequently viewed as a clash of binary claims, subject only to a sorting out of financial winners and losers. This popular vision was challenged by an ABA panel of experienced commercial mediators. ${ }^{2}$ Together they explored the opportunities for breaking out of this confining legalmold. Years of practice have taught them that many disputes are not just about money, even when money is the presenting issue.

When preparing the first edition in 2004 of my book, Mediation Representation, I gave attention to this persistent question when I framed a key theme as: "You have little chance of discovering whether a dispute is only about money if you approach the dispute as if it is only about money." 3 Whenever I lecture on the

* A version of this Article will appear in "Alternatives to the High Cost of Litigation," published by the International Institute for Conflict Prevention \& Resolution, in Fall, 2017.

1 Hal Abramson, Professor of Law, Touro Law Center, New York, N.Y. writes, teaches, and trains on negotiations and mediation. He has trained in eighteen countries on six continents. He also works as a commercial mediator and was selected for the International Who's Who of Commercial Mediation. For a full bio, see Tourolaw.edu/faculty/Abramson.

This Article arose out of a panel discussion: Legal Mediations are not only about Money: Mediators and Advocates as Problem Solvers. The discussion by experienced mediators took place at the ABA Section of Dispute Resolution Spring Conference held in New York, N.Y. on April 8, 2016. The panel consisted of Distinguished Fellows in the International Academy of Mediators (IAM): Birgit Sambeth Glasner, Geneva; Bennett Picker, Philadelphia; and Jerome Weiss, Cleveland. The program was organized and moderated by Hal Abramson in his capacity as IAM's Scholar-in-Residence. Bill Marsh, London was asked to contribute after publishing a critique of binary processes.

2 See id. on panelists: Birgit Sambeth Glasner, Ben Picker, and Jerry Weiss.

3 Harold Abramson, Mediation Representation-Advocating as a ProblemSOLVER 7 (3d ed., 2013). 
subject, I routinely get push back from attorneys and mediators who claim that most disputes are about money. Even though the book offers multiple responses, another way to reply is to ask experienced, highly-regarded commercial mediators.

This Article offers insights from four mediators at the front line of mediation practice-two from the United States and two from Europe. They are not part-time mediators with safe day jobs. Mediating is their day job. They are all Distinguished Fellows of the International Academy of Mediators ("IAM"). ${ }^{4}$

Collectively, they present a mindset for mediating that affords opportunities for uncovering needs and options that go beyond the presenting financial demands. Drawing on their years of experience, each contributor describes and illustrates how mediators can and must dig beneath the presenting claims to succeed in really resolving a dispute.

Each contribution was written independently, and yet the contributions offer remarkably similar critiques and observations, although each person brings to bear his or her distinctive perspective. As a group, they are sharply critical of binary processes like courts for resolving disputes and see binary processes as ones that mask the complexity of disputes and nuanced solutions. They also emphasize the importance of preparation and strongly endorse taking risks, being courageous, and probing deeply for the interests of the participants. Each of them also identify several of his or her favored techniques for moving beyond the mere financial exchange.

Bill Marsh focuses on the limitations and consequences of a binary process and the need to shape a better process that deals with the complexities of disputes. Jerry Weiss, focuses on the need to do more than just get the job done. Mediators should find the human beings that drive conflict and their resolutions. Birgit Sambeth Glasner gives attention to the need for courage and creativity to push participants out of their comfort zone to uncover more than presenting monetary issues. Bennett Picker saw mediation as about more than resolving a money dispute. It is an opportunity. He emphasized that mediators also should identify and overcome various non-monetary barriers to resolutions. I had the honor to moderate the program and incorporate their contributions into this article. Here are their insights.

\footnotetext{
4 See IAM at http://www.iqmed.org.
} 


\section{BILl MARSH}

The desire for the clarity and decisiveness that binary processes can produce can make them appealing. But, precisely because binary processes offer a win/lose, yes/no outcome (just like the courts), we need to be acutely conscious of their limitations and consequences.

\section{A. The First is the Swift Descent into Simplicity and Caricature}

Conflicts engender a descent into simplicity and caricature, and binary processes exacerbate that. When I mediate, I am often struck by how those involved appear to have reduced the sheer complexity of the situation to a series of simple (and apparently certain) propositions. Nowhere is this truer than with the history of events, with stories. However complex, multi-layered, and nuanced they may have been at the time; however much 'six of one and half a dozen of the other;' however much there may in fact be some shared accountability for what went on, both the conflict itself and the processes by which we address it (usually violence or litigation) often drive parties towards simplicity and caricature. By the way, if you doubt this, just look at the process of political elections!

Life is complex, and conflicts even more so. Do we not want conflict resolution processes that can handle complexity? Perhaps one of the great contributions mediators can make is to re-complexify (if that word exists), to re-introduce nuance.

\section{B. The Second Downside of Binary Processes is that They Make No Space for a Range of Options}

By definition, only two outcomes are possible. Win or lose. Sink or swim. Remain or leave. Being close (e.g. $48.1 \%$ to $51.9 \%$ in the Brexit referendum) is not enough. I realize that decisions need to be made. But they can also be deeply damaging. A few years ago, it was my great privilege to mediate the long-running

5 Bill Marsh is a leading international commercial mediator, based in the U.K. He also mediates ethnic, religious and political conflicts, and advises numerous governments and other international bodies on approaches to conflict and mediation. For more information, see BILL Marsh, International Mediator, (2017), http://www.billmarsh.co.uk. 
conflict in the Church of England about whether women could become bishops (they couldn't then; they can now). Like many institutions, the Church of England has a governance system which is quite 'parliamentary' in style. Because of that, the preceding decades had been marked by a "campaign" to permit women to become bishops, building up a head of steam towards a vote in the General Synod (the Church of England's "parliament"). Several times, the matter came up for a vote. In the usual way, votes were preceded by speeches. These speeches took the inevitable form of people speaking either for or against the motion. Each time, a vote was then taken. Each time, it was defeated. On the final occasion before mediated talks began, the vote was extremely close, but the proposal was still defeated. The body was profoundly divided. The pain was great.

Some eighteen months of mediated talks followed. What emerged was a series of options, far removed from the binary simplicity which had gone before. The options themselves were complex, but essentially made space for differing views, to differing degrees. Eventually the designated group involved in the talks (about forty representatives of all 'sides,' in total) arrived near (though not quite complete) unanimity on one option. They took that back to General Synod and jointly proposed it as the way forward. It passed comfortably. I was very moved to be in the public gallery at the time. Many of the speakers noted two things: (1) how the tone of the debate had radically altered from what had gone before, being now marked by a greater degree of mutual understanding and generosity of spirit, because of the extensive dialogue which had taken place; and (2) how much more appropriate it was to be voting on an option which had emerged from fulsome dialogue, and which attempted (successfully in the eyes of most) to make space for different views.

\section{The Third Feature of Binary Processes is that They Often Engender Decisions Motivated (at Least in Part) by Fear-The Fear of Losing}

Fear of losing is hardly surprising, given the limited options of win or lose. I see this so often when I mediate. And it is important for us to recognize it, because as a mediator, I want people to make good decisions-whatever those may be. Decisions made out of fear are rarely sustainable or wise. 
When I mediate, I often find myself encouraging parties-encouraging them to think hard, to make difficult decisions, to have uncomfortable conversations, to consider risks, and so on. And I use the word "encourage" literally. To "en-courage"-in other words to engender, build up, or enable a greater degree of courage. To try to ensure that wisdom, and not fear, becomes the primary motivating force in their decisions, or at least that fear is not the only one.

The need for courage extends beyond our role in individual disputes. The mediator's voice needs to be heard in society at large, and not just in individual disputes. We need to be "prophetic" in the best sense of that word-not as in prophesying or predicting the future, but holding up a challenge to the status quo. True prophets in every age have done that. And it always takes courage. Perhaps we need to challenge the nature of public discourse and decision-making more. After all, there will be no shortage of it over the coming years both in private and public matters, not least on the Brexit issue. And that task will require us first to understand the impact of binary processes - simplicity, limited options and fear-in order to be able to contribute to a discussion on a better process and results for the affected parties.

\section{JERRY WEISS ${ }^{6}$}

The back and forth of the distributive bargaining model that we are accustomed to, seems to my experienced eye, outdated and contrary to the interests of durable solutions. In two words, it is fatigued and fatiguing. Hand-to-hand combat too readily digresses in the 'bargaining process' of the argument, thereby continuing the competition and all of its negative forces. What results is akin to 'trial by mediation.' Add to this antiquated method the increasing velocity demanded by the market and supported by the warp speed technology of our time, and what results is a toxic mix. These forces elevate goals of closing, expedience, money and commerce to the detriment of the real people who are integral to the dispute and in whose control the terms, texture, quality, and spirit of the resolution resides.

6 Jerry Weiss was the first lawyer in Cleveland to dedicate his practice entirely to mediation. He mediates many high stakes, emotionally driven disputes and is recognized as a mediator who looks for the human beings behind the dispute. He also teaches aspiring lawyers in mediation representation and how to be problem-solvers. 
And yet, we neutrals can drift on in rote, almost mechanically, looking ahead to our 'next game' and thereby running the risk of losing, badly losing, the human virtues of the one we are playing at the moment. Durable resolutions, where the parties and products and processes are all served and where participants feel a sense of satisfaction are often lost, and what results is sadly a sense of inadequate closure with people feeling they need a bath. Mediation can be a punishing process that only continues to bruise the participants. The 'fighters' in the contest, usually lawyers, are trained to battle and thereby run the risk of losing sight of those elements that make conflict and its resolution human.

We can do better-much better! And it doesn't take much of a shift to affect the overall arc of a particular resolution process. We need only to be mindful of a few factors that are central to disputes and their resolution: intimacy, humanity, clarity and trust. None of these are usually found in the lexicon of commercial or other disputes and yet, all disputes and resolution processes are indeed intimate and human events with complex human interaction at their core. Likewise, it is clear to many of us who have been doing this for a while that durable processes require good communication, where more than words and content matter, but rather where tone and non-verbal communication also are key. That said, clarity and articulation of the message are too often missing, with disputants and their representatives often going at it without a clear idea of what is really intended by their counterparts. Time and discipline are often not taken because of pressures to "get it done" or worse, fear of having difficult conversations.

Concentrating on these factors can help build a foundation supporting that meditative moment found in the best resolution processes and practices, where the people in the room begin to feel that they might be able to break the constraints of past conflict and rely on their disputant opponents as partners. Real peace transcends a mere signature on a piece of paper. Real peace presents the ability to move forward in a constructive way, without the burden and deconstruction of the conflict. We can refer to this shift in mediation as trust and as a basis for an agreement that can endure. The day after the resolution agreement, where satisfaction comes into play, whether in terms of action or simply a sense that disputants have done something they can live with, some sense of contentment, is much more important than the agreement itself. Such action and trust - a dynamic and living human process, or at least a bridge to such thinking-are goals we should aspire to. 
There are no silver bullets or simple tricks that I employ in order to draw people into a more constructive and human process. Rather, I try to concentrate on some keys, exemplify them in my behavior, and count on the fact that people will recognize their virtue and maybe, to some extent, mirror and integrate these behaviors and understandings. Here are a few suggestions:

- Running the room and establishing guidelines that expect best practices and behavior. This starts with the letter of engagement and continues to the actual meeting and encounter, where the neutral can make express statements about these expectations.

- Making clear that one expects positions and opinions to be explained. Lawyers are notorious at blurring the lines between fact and opinion and position and truth. Bringing out clear distinctions goes a long way to point out how different the theater of the lawsuit may be from the necessary partnerships and virtues of resolution.

- Talking about partnerships and how they differ from adversaries, who will never agree, and describing the disputants as partners and asking them to envision themselves as such.

- Complimenting and maybe even rewarding courageous or noble behaviors, and even polite behaviors. This may be as minor as telling people how privileged we are to have them share the dispute and opportunity to help them. Conversely, to have the courage to politely discourage and prevent bad behaviors, either directly or privately, utilizing a level tone in a helpful and reflective manner.

- Expressly promoting the need and desire to get the conflict resolved and moving forward. It is helpful to promote open doors and clear communication including attaching articulate messages to any exchange of numbers that adds meaning to those numbers. In general, we need to generate clarity during the progression of the negotiating process. Listening better and knowing that as neutrals, who think we have the idea of where the fix lies, we really may not. Pacing the process-which often translates into slowing it—so that people can "listen" with their ears and eyes is very helpful. I have written several blogs on listening that can be found at the IAM website. ${ }^{7}$ Having courage to say 'no,' politely, but firmly to people who want to avoid difficult conversations because of fear or just plain bad habits, by quietly prodding and encouraging them and complimenting them once they have successfully had them. 
- Being transparent about common fears that attend disputes and their processes and sharing our own concerns about with disputants in order to relate and make a human connection instead of fighting the kind denial that is so often the result of these common fears. Reassuring people that that "bad place" is a common feeling and may not be so bad.

Saying hello and goodbye together, and encouraging people that such things can't hurt and they might help in setting a tone of reciprocity, decency and fairness. Along these lines, joint sessions should be encouraged so as to begin tearing down the barriers that conflict builds up. Dining together with both sides without discussing merits can help disputing parties become partners. I have seen it happen. If they insist on working during that half hour or hour, then have them work at listing those elements of an agreement that are not burdened with rancor or a high degree of contest and leaving the tough issues for later. This can be a constructive exercise as it gives a start on things people can agree to and partner on and will set a better tone for more challenging aspects.

None of this is necessarily easy. It all requires a disciplined integration into practice over time and awareness of oneself and the totality of the room we are in-being in the moment. It also requires us to recognize that most of what we do is based on trust building, both vis a vis the neutral and all sides of the dispute, and also and perhaps more importantly, among those sides.

All of which begs the question: whether our goals should exceed 'merely getting it done.' This is a philosophical choice, and one that I have made as I increasingly believe that giving human beings the opportunity to start viewing opponents, who they have been probably vilifying and dehumanizing by virtue of what the fight does to us, as something other than the devil. In a somewhat vulgarized brain science nomenclature, this probably translates into allowing those PRIMAtive aspects of our beings to be tamed by elevated, human and reflective virtues. By understanding and employing these methods and by picking away at the dispute piece by piece over time, we allow ourselves to find the human beings that drive conflict and their enduring resolution. 
IV. Birgit Sambeth Glasner ${ }^{8}$

\section{A. Case Study}

\section{What If? Let's Be Creative ...}

What if you were requested to mediate an international commercial case about the sale of a chemical subsidiary of a German company to an English buyer, a publicly listed company on the London Stock Exchange. The $€ 59$ million share and asset purchase agreement between the two European companies, and the numerous related commercial contracts, ran into large problems. They included allegations about the accuracy of financial information, misleading profit transfers, overstatement of efficiency claims, and misrepresentation of building and plant, stock shortfall, and employee grievances. It also included threats of huge interest payments and damages. If so, it would be the perfect time, as a mediator, to take a step back, help the parties think 'outside the box' and structure an appropriate process to enable the resolution of their differences, not only on the surface but in-depth.

\section{But How?}

First, recall that a conflict is not (and almost never is . . .) about money. Second, be aware that positional bargaining is not an adequate dispute resolution method. As Albert Einstein once said: "We can't solve the Problems by using the same kind of thinking we used when we created them." Third, it needs some courage on the part of the mediator to lead the parties and their attorneys through a creative process where the discussion about money is only its very final act. Fourth, every step towards success is proper preparation. As "location, location, location" is the slogan of real estate agents, "preparation, preparation, preparation" should be the slogan of any mediator for whatever topic and dispute size.

Preparing for the mediator means of course becoming knowledgeable about the dispute, including the interests and needs of each of the parties, the risks they are facing, and the opportunity

8 Birgit Sambeth Glasner is listed as number one Mediator of Switzerland by Who's Who. She is a full time mediator, the Vice President of the Swiss Chamber for Commercial Mediation, a Distinguished Fellow of the International Academy of Mediators as well as a member of the CPR European Advisory Board. As an International Mediator, she is accredited by the Geneva Courts as well as by IMI, CEDR, CPR, SCIA, CMAP and listed with ICC and WIPO and as INSOL Insolvency Mediator. She mediates in French, German, English and sometimes Spanish. 
afforded by the mediation process. A mediator needs to sincerely dig deep, listen and understand.

Moreover, preparing for the parties and their attorneys means not only investing time and energy in understanding their own interests, needs, risks and opportunities, but also and very importantly, those of the other side. It is also means assessing each one's Best Alternatives to a Negotiated Agreement("BATNA") by means of objective criteria (such as time, costs, consequences, damages) and to make a first 'reality check.'

Preparing can take place with all the attorneys (possibly with their clients) during a joint phone call when organizational issues as well as parties' expectations towards the mediation process and the role of the mediator are discussed when structuring together an efficient and realistic process.

Subsequent private preparation meetings or calls with each of the parties will enhance the overall understandings of the mediator and the parties. Furthermore, this direct communication in a safe environment usually fosters the necessary trust towards the mediator and the mediation process, allowing creative tools and risk-taking in the process.

If at this early stage of meetings, where the focus is on preparation, if it is still important to talk about money, it will finally be the time!

\section{Let's Not Talk About Money Yet!}

In the case mentioned above, the parties and their attorneys were focused on the financial features of their dispute while fighting over accounting issues. One of the parties had requested no less than sixteen legal, accounting and financial specialists to sit at the mediation table. After a thorough preparation, we met in Paris at an impressive round table accommodating twenty people (the other party appeared at the mediation table with two counsels). At the start, I recalled the strict confidentiality of the mediation process, and we jointly fixed the time limit of our mediation day until 8:00 pm.

Immediately after the opening of the joint session and the 'opening statements' of the parties, I suggested taking the next two hours to "discuss anything but money".

\section{Stupor in the Room!}

If so agreed, what would the eighteen other people in the room do during this time, other than question their remuneration 
during that 'lost' time? Boosted by parties' trust gained during the preparation phase, I started asking some open questions to the principals on how they usually conduct their respective business and which values they have in doing so. Astonishment (and for the attorneys in the room, even some polite and less courteous discontentment) was the response to my inquiry. I stayed this course by assisting the principals to enter into a meaningful discussion leading to a comprehensive expression of their shared values and their interests, and needs around the troubled deal. Later in the discussion, the seller stood up and said with a trembling voice, "If you are questioning the financials of the deal, it is as if I would have lied to you and I am a crook! You should know that this is intolerable to me as we have a strict code of conduct in our family business which I am very proud of." He then sat down, emotionally exhausted.

The purchaser immediately realized that it was time to reply: "I am sincerely sorry. This is not what I wanted to say and certainly not the message I wanted to convey to you, but I have some questions about the way you did your calculations and your representations. I would like to discuss those openly with you."

Trust was rehabilitated in the room. This had an immediate positive impact on the process and my role as mediator was almost over.

I spent the rest of the day facilitating this discussion, assisting the parties in structuring a new deal and organizing their tasks, responsibilities and timing for finalizing it. And the mediation concluded the same day with a settlement at 7:30 pm.

\section{B. Some Lessons Learned}

Each of us, as mediators, use favored techniques to uncover interests and options that go beyond presenting financial demands.

However, the more creative mediators dare to be, the more trust in the mediator and process is needed in the room for the parties and obviously, their attorneys to follow that path. And therefore, preparation is key. We as mediators are hired to take risks to push parties to do what they may resist doing. Otherwise, the process is just positional bargaining with no real added value.

Attorneys may not be at ease with such a process, which often pushes them out of their comfort zone as the mediation addresses non-legal components of the dispute where attorneys can fear losing control over their clients. However, attorneys play an impor- 
tant role in mediations, especially in coaching their clients and performing reality checks. Good preparation with the attorneys and active engagement in the process enhances its effectiveness and gives the attorneys a sense of understanding and engages them. Good preparation also offers mediators a benefit that they worry about losing when pushing participants-likelihood of repeat business.

\section{Bennett Picker ${ }^{9}$}

Regrettably, in too many mediations today, both advocates and party representatives view mediation with the same lens as they view litigation. With a one-dimensional perspective, their focus is on the summary judgment issues, the risks, the costs and the dollars. In private meetings and caucuses, too many mediation advocates focus exclusively upon the strength of their legal positions. When we get to the negotiation stage, too many mediation advocates seem to be inspired by a line from the movie Jerry McGuire: "Show me the money!" So, if it's not just about the money, what else is it about? Of course, Mediation 101 teaches us that the process offers an opportunity to explore underlying interests and search for interest-based, creative solutions, solutions unavailable in the win-lose environment of litigation. For example, in a recent employment case that was framed in terms of money, after an exchange between a tenured professor who had been summarily dismissed and the Provost of the University, the University rehired the professor when it concluded it had acted prematurely, based on incomplete information.

Similarly, commercial agreements can be renegotiated, patent disputes can be resolved by pooling agreements, and outdated partnership agreements can be reformed to reflect current business realities. While the potential for business solutions should be obvious to disputants, it is often less so to their lawyers who need to be reminded to take a multi-dimensional view of a dispute that appears to be all about money. Even when mediation advocates and

\footnotetext{
9 Bennett G. Picker is a full time mediator and arbitrator who is a Distinguished Fellow of the International Academy of Mediators, a member of the CPR Panel of Distinguished Neutrals and a member of the Master Mediator Panel of the American Arbitration Association as well as several of its arbitration panels. He is the author of, "Mediation Practice Guide: A Handbook for Resolving Business Disputes," published by the Dispute Resolution Section of the American Bar Association.
} 
business clients recognize the potential for business solutions to business disputes, they are far less aware of the numerous barriers to resolution that often are not about the legal issues and not even about the money. In my experience, uncovering these hidden barriers is often the most critical work that we, as mediators, must do.

\section{A. Hidden Non-Monetary Barriers to Resolution}

While the list of possible hidden barriers includes a host of process, psychological and merit obstacles, I have found the following to be the most prevalent:

\section{Barriers Resulting from Relationships Between Counsel and Client}

Professor Gerry Williams, a teacher of negotiations, studied the negotiating behavior of over twenty lawyers for seven years and concluded that, in rank order, the principal barrier to resolution was not a disconnect between a plaintiff and defendant. Rather, it was a disconnect between a lawyer and client. Lawyers can inflate expectations made at the outset of the relationship, be unwilling to report to the client the weaknesses in a case, or fail to report the status of litigation as the litigation unfolded. On many occasions, counsel have turned to me at the end of a mediation and said: "thank you for telling my client what I could not say," or "I told my client about the weaknesses and was told 'I thought you were my lawyer.'" Interestingly, Professor Williams found that counsel's interest in fees often had an impact on the recommendation of counsel or the decision of the client. I have found this to be the case, especially when the arrangement is a contingent fee.

\section{Emotional Barriers}

Quite often, anger, frustration, resentment, guilt, jealously and so many other emotions are at the heart of a dispute. As just one example, I mediated a dispute between two brothers who owned a large, closely held business for decades. Over the years, the brother who was not in control repeatedly filed lawsuits alleging breaches of fiduciary duties. In mediation, I met alone with the two brothers, and after a while, the brother who filed the action said "you know, mother really liked you better." This response led to the first meaningful conversation between the two brothers in years. With this on the table, we were able to resume negotiations 
and find a lasting resolution. In other mediations, I have found that apologies, when sincere, have reduced the anger of the other side and opened the door for meaningful settlement discussions.

\section{Barriers Resulting from Disagreements Between Stakeholders On One Side}

Quite often, disagreements among several party representatives on one side can be the principal barrier to settlement. Each party representative may have a different priority. In a recent dispute involving a long-term supply agreement, the general counsel was looking for a large sum of money for the plaintiff, the business manager was looking for a court decision to vindicate her decision to pull out of the agreement, and the CEO was looking for a restructured agreement, arguing that Wall Street values long term streams of revenue more highly than large sums of cash. Again, this dispute was not about how much money the defendant would pay. Instead, much of my work focused on mediation among the representatives of one side.

\section{Cognitive Barriers}

In almost every mediation, I have observed cognitive illusions and irrational attachments to positions distort objective evaluations and impact settlement decisions. These barriers are usually invisible to the other side. Studies at the Harvard PON and at the Wharton School of Business demonstrate that advocacy bias makes it difficult for a party with an interest in the outcome of a dispute or their lawyers to make a completely objective evaluation of a dispute. Parties view their facts selectively ("selective perception") and spend almost all of their time mining their own best arguments. Their evaluations are distorted by optimism bias, certainty bias, assimilation bias, hindsight bias, reactive devaluation and so many other errors of judgment.

\section{B. Techniques to Overcome the Hidden Barriers}

Given that many mediations that initially appear to be only about the money turn out to be otherwise, what are the techniques a mediator can employ to uncover the underlying needs and opportunities for resolving disputes? While the answer would constitute a syllabus for a one-week course, I would like to offer a few big 
picture approaches that I have found to be helpful in uncovering the hidden barriers and drivers of resolution.

\section{Preparation}

In addition to any possible exchanges by the parties, I invariably insist on confidential 'eyes only,' submissions which go well beyond the claims and defenses and the 'money.' In this confidential submission, I ask counsel to address potentially hidden barriers that need to be addressed. Among these are personality issues, the need for confidentiality, links to an unrelated dispute, strategic issues, accounting and audit issues, emotional issues, need for vindication, internal company issues, and future implications.

\section{Conferencing Before Mediation Session}

In almost every dispute, after I have read the submissions, I meet by phone with counsel to further explore the interests and potential barriers that may exist. Aside from the merit issues, I encourage candid responses to questions such as, "can you tell me more about your client"? At times, I receive replies such as, "my client is the real problem"; or, "I need your help"; or, "my client is so angry with the other side that I'm not sure we can be in the same room"; or, "an apology would go a long way in helping to get this matter resolved"; or, "let me tell you about the other side's private agenda."

\section{Mediation Session: Ex-Parte Meetings Before Joint Session}

Many years ago, I began the practice of meeting with parties before commencing a joint session. I quickly learned how powerful these meetings can be for building trust. I typically engage the decision-maker, and we talk about anything other than the dispute. We can talk about sports, opera, travel or our families. On more than one occasion, party-representatives have shown me pictures of their grandchildren. With a bond formed at the outset, I have found that parties will be far more open with me once we reach the caucus and resolution stages.

\section{Caucus Sessions - Probing for Drivers and Barriers of Resolution}

With a dose of coaching, I begin exploring with each side the potential for settlement. Regardless of the path we take in negotiations, I continue to explore whether there are psychological, relational or cognitive issues that need to be addressed. If the parties 
need to vent, I will listen, acknowledge and empathize. If there are relational issues (either party-to-party or within one side), I will take the time to address these issues. If the evaluations of one or both parties are distorted, I will employ various techniques to spur parties to reconsider their assessments.

I was once asked to explain mediation in one word. Without hesitation, I said "opportunity." Mediation can afford the opportunity to develop issues that otherwise would take months or years in litigation; save time and money; preserve relationships; and search for solutions not available in litigation or arbitration. I often mention the opportunities in mediations because no one wants to lose an opportunity. In order to maximize the mediation opportunity, it is incumbent upon the mediator, in addition to addressing the legal issues, and focusing on the money, to work with the parties to address the other issues, concerns, and interests for a successful and enduring resolution.

\section{Conclusion by Hal Abramson}

The experiences and insights of these mediators may inspire others who are not so inclined to look beyond the financial dimension of disputes. For those mediators who tend to function like private settlement judges, their guidance suggests a pathway for doing much more. Their comments and techniques should give reticent mediators confidence to trust the mediation process and employ more daring techniques that may produce more enduring and satisfying resolutions. 